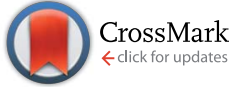

Cite this: RSC Adv., 2017, 7, 14413

Received 29th January 2017

Accepted 25th February 2017

DOI: $10.1039 / \mathrm{c} 7 \mathrm{ra01249g}$

rsc.li/rsc-advances

\section{In situ X-ray absorption fine structure study on the polymerization of isoprene assisted by $\mathrm{Nd}$-based ternary catalysts $\uparrow$}

\author{
H. L. Guo, ${ }^{\text {ab }}$ J. F. Bi, ${ }^{c}$ Q. Y. Wu, ${ }^{\text {b }}$ J. Y. Wang, ${ }^{\text {b } W . ~ Q . ~ S h i, ~}{ }^{\text {, X. Q. Zhang, }}{ }^{\star c}$ S. C. Jiang ${ }^{\star a}$ \\ and Z. H. Wu*b
}

$\mathrm{Nd}$-based ternary catalysts are widely used for the polymerization of isoprene in rubber industry, however structure information during the polymerization of isoprene as well as the catalytic mechanism are still ambiguous. In this paper, the in situ XAFS technique was used to extract the local atomic structure around the $\mathrm{Nd}$ center of the catalyst consisting of $\mathrm{Nd}(\text { vers })_{3}, \mathrm{AlEt}_{3}$, and $\mathrm{Al}\left({ }^{i} \mathrm{Bu}\right)_{2} \mathrm{Cl}$. Theoretical calculations were used to verify the structure changes in the alkylation process. Four catalysts with different alkylaluminums $\left\{\mathrm{AlEt}_{3}, \mathrm{Al}\left({ }^{n} \mathrm{Oct}\right)_{3}, \mathrm{Al}\left({ }^{i} \mathrm{Bu}\right)_{3}\right.$, and $\left.\mathrm{Al}\left({ }^{i} \mathrm{Bu}\right)_{2} \mathrm{H}\right\}$ were, respectively, used for the polymerization of isoprene. The results demonstrate that the substitution of $\mathrm{Nd}-\mathrm{C}$ for $\mathrm{Nd}-\mathrm{O}$ bonds is reasonable in the alkylation step. The structural evolutions in the alkylation and chlorination steps, as well as in the polymerization processes of isoprene are all similar for these $\mathrm{Nd}$-based ternary catalysts with different alkylaluminum components. In the polymerization process of isoprene, there are only about $2 \mathrm{Nd}-\mathrm{Cl}$ bonds at $2.85 \AA$ and $1-2 \mathrm{Nd}-\mathrm{C}$ bonds at $2.42 \AA$ around the $\mathrm{Nd}$ centers which are in a monomer state. The $\mathrm{Nd}-\mathrm{C}$ bonds can be attributed to the contribution of isoprene. This highly-opened structure of the $\mathrm{Nd}$ active centers activates greatly the catalytic activity of the $\mathrm{Nd}$-based ternary catalysts. A conjectural catalytic mechanism for the polymerization of isoprene has been deciphered on the basis of the in situ XAFS results. This study is expected to be helpful for the improvement and application of the $\mathrm{Nd}$-based ternary catalysts.

\section{Introduction}

The stereospecific polymerization of conjugated dienes (butadiene, isoprene) is an attractive research subject and has drawn much attention from both academic and industrial researchers., High cis-1,4-content ${ }^{3}$ is very important for the mechanical and dynamic properties of the synthetic rubber which has been widely used for a variety of technical rubber goods and tire parts. Ndbased catalysts were used in the polymerization reactions ${ }^{4-9}$ of the rubber industry, because they can display high stereoselectivity $^{10-14}$ of the polymer. However, it is still unclear for the polymerization mechanism of conjugated dienes catalyzed by Ndbased catalysts. Therefore, the polymerization process of conjugated dienes and the catalytic mechanism of Nd-based catalysts always attracts considerable interest.

${ }^{a}$ School of Materials Science and Engineering, Tianjin University, Tianjin 300072, China.E-mail: scjiang@tju.edu.cn

${ }^{b}$ Institute of High Energy Physics, Chinese Academy of Sciences, Graduate University of Chinese Academy of Sciences, Beijing 100049, China. E-mail: wuzh@ihep.ac.cn

${ }^{c}$ Research Center of High Performance Synthetic Rubber, Changchun Institute of Applied Chemistry, Chinese Academy of Sciences, Changchun 130022, China. E-mail:xqzhang@ciac.ac.cn

$\dagger$ Electronic supplementary information (ESI) available. See DOI: 10.1039/c7ra01249g
The active catalyst species of the Nd-based catalysts and the chemical role of catalyst components kept unknown. ${ }^{15}$ To study the structure of Nd-based precursor and/or the active center of catalysts, Kwag et al. ${ }^{16-18}$ attempted ultraviolet-visible absorption spectra, matrix-assisted laser desorption/ionization time of flight mass spectrometry (MALDI-TOF-MS), and density functional calculations (B3LYP/CEP-31G). A possible mechanism for the catalytic polymerization was proposed. They pointed out that the pseudoliving property of the $\mathrm{Nd}$-based catalyst originates from the hybrid $\mathrm{Nd}-\mathrm{C}$ bonds with both covalent and ionic characters as well as the trivalent state of neodymium during the activation process. By analyzing the reaction kinetics of the polymerization of 1,3-butadiene initiated by the ternary ZieglerNatta catalyst system, Friebe et $a .^{15,19-21}$ considered that it was a living polymerization with fast and reversible chain transfer. The aluminum cocatalyst was speculated to have an activating effect by either increasing the concentration of active $\mathrm{Nd}$ or by increasing the number of active sites per $\mathrm{Nd}$. Anwander et al.,22-26 focused on the precise structure of $\mathrm{Nd}-\mathrm{Al}$ compounds. Elaborated crystal samples were used for X-ray structure determination. They found the first structural evidence about the carboxylate-alkyl interchange. A modified insertion mechanism for isoprene polymerization was proposed on the base of structural information. Besides, Sabirov, ${ }^{27,28}$ Iovu, ${ }^{29,30}$ Evans, ${ }^{10}$ and 
many researchers, ${ }^{31-33}$ also made efforts to figure out the active center and/or polymerization mechanism of Nd-based catalyst. In fact, understanding the working mechanism of the complex Nd-based catalysts cannot do without in situ structural information and structure evolution. Typical Nd-based catalyst system for rubber industry ${ }^{\mathbf{1 4 3 4 - 3 6}}$ comprises neodymium salt, alkylating cocatalyst, and chlorinating cocatalyst. The three components were successively added to alkyl solvent to form three typical activation steps. Because of the flammable and explosive attributes of some components in the Nd-based ternary catalysts, in situ probe techniques suitable for the structural characterization of Ndbased catalysts are quite scarce. Therefore, the in situ and quantitative structure information of Nd-based ternary catalysts in working status almost remains an uncharted area. Fortunately, Xray absorption fine structure (XAFS) is a powerful technique $e^{37-39}$ to investigate the local atomic structures of solid and liquid samples, which can be used to extract the partial atom-pair distribution information around the center (or absorption) atom. ${ }^{40}$ As we known, Kwag et al. ${ }^{18}$ utilized XAFS technique to characterize the structure of the Nd-based ternary catalyst containing neodymium neodecanoate $\left\{\mathrm{Nd}(\text { vers })_{3}\right\}$, triisobutyl-aluminum $\left\{\mathrm{Al}\left({ }^{i} \mathrm{Bu}\right)_{3}\right\}$, chlorodiethyl aluminium $\left\{\mathrm{AlEt}_{2} \mathrm{Cl}\right\}$ in $n$-heptane solution for the first time. In their XAFS measurements, the samples were rapidly frozen to $-78{ }^{\circ} \mathrm{C}$ at each activation steps and then were used to collect the XAFS spectra in transmission mode. Some distinct spectral changes can be found from the X-ray-absorption nearedge structure (XANES) spectra and the corresponding Fourier transform (FT) spectra of the three different activation steps although the quantitative structural information were not provided. In our previous work, ${ }^{41}$ in situ XAFS technique was used to detect the liquid structures of the Nd-based ternary catalyst containing $\mathrm{Nd}(\text { vers })_{3}, \mathrm{Al}\left({ }^{i} \mathrm{Bu}\right)_{3}$, and chlorodiisobutyl aluminium $\left\{\mathrm{Al}\left({ }^{i} \mathrm{Bu}\right)_{2} \mathrm{Cl}\right\}$ in hexane solvent. The quantitative structural evolution around $\mathrm{Nd}$ center was obtained at the three activation steps. This research confirms a consensus that partial $\mathrm{Nd}-\mathrm{C}$ bonds substitute for $\mathrm{Nd}-\mathrm{O}$ bonds in the alkylation process and partial $\mathrm{Nd}-\mathrm{Cl}$ bonds are formed in the chlorination process for liquid $\mathrm{Nd}$ based ternary catalysts. Even so, we think that the ratio of the formed $\mathrm{Nd}-\mathrm{C} / \mathrm{Nd}-\mathrm{O}$ bonds in the alkylation process and their bond lengths are possibly changeable with the changes of alkylaluminium concentration in the solution and the alkylaluminium species, which could lead the difference of polymer performance. Form this point of view, a comparative study for different Ndbased ternary catalysts is still worthy. It is more important that the in situ structural information of polymerization with Nd-based ternary components as catalyst is absolutely desired, which could be used to clarify the polymerization mechanism of synthetic rubber.

In this paper, the structural evolution of the Nd-based ternary catalyst containing $\mathrm{Nd}(\text { vers })_{3}$, triethylaluminum $\left\{\mathrm{AlEt}_{3}\right\}$, and $\mathrm{Al}\left({ }^{i} \mathrm{Bu}\right)_{2} \mathrm{Cl}$ was briefly checked. Computational chemistry is used to firm the alkylation process. The research emphasis is placed on the polymerization reaction of isoprene. In situ XAFS technique is used to detect and compare the Nd-center structure changes of four different Nd-based ternary catalysts during the polymerization processes of isoprene (IP). This study is expected to give insight into the polymerization mechanism of isoprene with the assistance of Nd-based ternary catalysts.

\section{Experiments}

\subsection{Sample preparation}

To remove the potential moisture, $n$-hexane was first dried by molecular sieves $(4 \AA)$. $\mathrm{Nd}(\text { vers })_{3}$ solution with a concentration of $0.3080 \mathrm{~mol} \mathrm{~L}^{-1}$ was adopted in the experiment. $\mathrm{AlEt}_{3}$, trioctylaluminum $\quad\left\{\mathrm{Al}\left({ }^{n} \mathrm{Oct}\right)_{3}\right\}, \quad \mathrm{Al}\left({ }^{i} \mathrm{Bu}\right)_{3}, \quad$ diisobutylaluminum hydride $\left\{\mathrm{Al}\left({ }^{i} \mathrm{Bu}\right)_{2} \mathrm{H}\right\}$ and $\mathrm{Al}\left({ }^{i} \mathrm{Bu}\right)_{2} \mathrm{Cl}$ were purchased from Akzo Nobel and Aldrich respectively. In order to check the concentration effect of alkylaluminum, $\mathrm{AlEt}_{3}$ in hexane solution was mixed with $\mathrm{Nd}$ (vers) $)_{3}$ solution in mole ratios of $1: 1,2.5: 1$, and $10: 1$ to form Sample A1, A2, and A3. Further, $\mathrm{Al}\left({ }^{i} \mathrm{Bu}\right)_{2} \mathrm{Cl}$ in hexane solution was added to Sample A3 in a mole ratio of $3: 10: 1$ to form Sample A4 for checking the chlorination effect. To simulate the polymerization reaction of IP in the presence of Nd-based ternary catalyst, IP was added into Sample A4 (homogeneous catalyst) in a mole ratio of $10: 3: 10: 1$ to form Sample B1. Similarly, $\mathrm{AlEt}_{3}$ in Sample B1 was, respectively, replaced by $\mathrm{Al}\left({ }^{n} \mathrm{Oct}\right)_{3}, \mathrm{Al}\left({ }^{i} \mathrm{Bu}\right)_{3}$, and $\mathrm{Al}\left({ }^{i} \mathrm{Bu}\right)_{2} \mathrm{H}$ to form Sample B2, $\mathrm{B} 3$, and $\mathrm{B} 4$. The latter four samples are operated used to compare the polymerization processes of IP with different Ndbased ternary catalysts. All the samples are operated at room temperature and summarized in Table 1.

\subsection{XAFS measurements}

X-ray absorption spectra of $\mathrm{Nd} \mathrm{L}_{\mathrm{III}}$-edge were collected at beamline 4B9A of the Beijing Synchrotron Radiation Facility (BSRF). A moistureproof and adjustable-thickness liquid sample-cell ${ }^{41}$ was used for the in situ XAFS measurements. The Nd-L $\mathrm{L}_{\text {III }}$ edge XAFS spectra of all the samples were collected in transmission mode at room temperature. The storage ring was run at $2.5 \mathrm{GeV}$ with an electron current of about $100 \mathrm{~mA}$. The incident X-ray beam was monochromatized by a $\operatorname{Si}(111)$ double crystal monochromator with energy resolution $(\Delta E / E)$ of about $2 \times 10^{-4}$. The X-ray intensities before and after sample absorption were monitored with ion chambers. The obtained XAFS data were analyzed by using the IFEFFIT program. ${ }^{42}$ FEFF code $^{43}$ was used to calculate the reference XAFS spectra.

Table 1 Sample ingredient of the Nd-based ternary catalyst hexane solutions

\begin{tabular}{lll}
\hline Sample & Ingredient & Mole ratio \\
\hline $\mathrm{A} 1$ & $\mathrm{AlEt}_{3}+\mathrm{Nd}(\text { vers })_{3}$ & $1: 1$ \\
$\mathrm{~A} 2$ & $\mathrm{AlEt}_{3}+\mathrm{Nd}(\text { vers })_{3}$ & $2.5: 1$ \\
$\mathrm{~A} 3$ & $\mathrm{AlEt}_{3}+\mathrm{Nd}(\text { vers })_{3}$ & $10: 1$ \\
$\mathrm{~A} 4$ & $\mathrm{Al}\left({ }^{i} \mathrm{Bu}\right)_{2} \mathrm{Cl}+\mathrm{AlEt}{ }_{3}+\mathrm{Nd}(\text { vers })_{3}$ & $3: 10: 1$ \\
B1 & $\mathrm{IP}+\mathrm{Al}\left({ }^{i} \mathrm{Bu}\right)_{2} \mathrm{Cl}+\mathrm{AlEt}{ }_{3}+\mathrm{Nd}(\text { vers })_{3}$ & $10: 3: 10: 1$ \\
$\mathrm{~B} 2$ & $\mathrm{IP}+\mathrm{Al}\left({ }^{i} \mathrm{Bu}\right)_{2} \mathrm{Cl}+\mathrm{Al}\left({ }^{n} \mathrm{Oct}\right)_{3}+\mathrm{Nd}(\text { vers })_{3}$ & $10: 3: 10: 1$ \\
$\mathrm{~B} 3$ & $\mathrm{IP}+\mathrm{Al}\left({ }^{i} \mathrm{Bu}\right)_{2} \mathrm{Cl}+\mathrm{Al}\left({ }^{i} \mathrm{Bu}\right)_{3}+\mathrm{Nd}(\text { vers })_{3}$ & $10: 3: 10: 1$ \\
$\mathrm{~B} 4$ & $\mathrm{IP}+\mathrm{Al}\left({ }^{i} \mathrm{Bu}\right)_{2} \mathrm{Cl}+\mathrm{Al}\left({ }^{i} \mathrm{Bu}\right)_{2} \mathrm{H}+\mathrm{Nd}(\text { vers })_{3}$ & $10: 3: 10: 1$
\end{tabular}




\section{Results and discussion}

\subsection{Nd-based ternary catalyst}

Generally, Nd-based ternary catalysts consist of neodymium salt, alkylaluminum, and chlorine source for rubber industry. By altering the alkylaluminum component, different Nd-based ternary catalyst systems can be achieved. In our previous research, ${ }^{41}$ a $\mathrm{Nd}$-based ternary catalyst comprising $\mathrm{Nd}\left(\right.$ vers) ${ }_{3}$, $\mathrm{Al}\left({ }^{i} \mathrm{Bu}\right)_{3}$, and $\mathrm{Al}\left({ }^{i} \mathrm{Bu}\right)_{2} \mathrm{Cl}$ was prepared, which is marked as Catalyst-I. The local structure change around Nd center was detected by using in situ XAFS technique. The alkylation and chlorination structures in the different activation steps were extracted from the in situ XAFS spectra. It is generally recognized that the structure evolution is similar in different activation steps when the alkylaluminum in the Nd-based ternary catalyst is replaced by another alkylaluminum. To check the possible change caused by different alkylaluminum components, the Nd-based ternary catalyst comprising $\mathrm{Nd}$ (vers) ${ }_{3}$, $\mathrm{AlEt}_{3}$, and $\mathrm{Al}\left({ }^{i} \mathrm{Bu}\right)_{2} \mathrm{Cl}$ was prepared in this paper, which is marked as Catalyst-II. In situ XAFS technique has been used to characterize the structural change of Catalyst-II with the concentration of $\mathrm{AlEt}_{3}$ component or activation steps. For simplicity, only the structural comparison between Catalyst-I and Catalyst-II will be discussed below. The detailed structural information of Catalyst-II is summarized in the ESI. $\dagger$

For Catalyst-II, the $\mathrm{Nd}-\mathrm{O}$ coordination number is, respectively, 4.9, 4.4, 1.5 and the $\mathrm{Nd}-\mathrm{C}$ coordination number is, respectively, 3.8, 4.3 to 4.0 when the mole ratio of $\mathrm{AlEt}_{3}$ : $\mathrm{Nd}$ (vers) ${ }_{3}$ in hexane solution is, respectively, $1: 1,2.5: 1$, and $10: 1$. The corresponding $\mathrm{Nd}-\mathrm{O}$ and $\mathrm{Nd}-\mathrm{C}$ bond lengths are almost unchanged with the concentration of $\mathrm{AlEt}_{3}$, which are, respectively, kept at 2.38 and $2.58 \AA$ A. For Catalyst-I, the $\mathrm{Nd}-\mathrm{O}$ coordination number is $4.3,2.2$ and the $\mathrm{Nd}-\mathrm{C}$ coordination number is $4.0,3.9$ with the mole ratio of $\mathrm{Al}\left({ }^{i} \mathrm{Bu}\right)_{3}: \mathrm{Nd}(\text { vers })_{3}$ at $2.5: 1$ and $10: 1$, respectively. The $\mathrm{Nd}-\mathrm{O}$ and $\mathrm{Nd}-\mathrm{C}$ bond lengths are also 2.38 and $2.58 \AA$ without change. By comparing the two catalysts, it can be found that both of them have almost the same local atomic structures. The alkylation process makes that partial $\mathrm{Nd}-\mathrm{O}$ bondings can be replaced by $\mathrm{Nd}-\mathrm{C}$ bondings with the addition of alkylaluminum into the $\mathrm{Nd}(\text { vers })_{3}$ hexane solution. There are about $4 \mathrm{Nd}-\mathrm{C}$ atom-pairs located at $2.58 \AA$. The number of Nd-O atom-pairs with bond length of $2.38 \AA$ decreases from 4 to about 2 as the mole ratio of $\mathrm{Al} / \mathrm{Nd}$ increasing from $2.5: 1$ to $10: 1$. A slight difference is that the $\mathrm{Nd}-\mathrm{O}$ coordination number seems to have a faster descent rate in CatalystII than Catalyst-I, which implies that the oligomeric structure in original $\mathrm{Nd}(\text { vers })_{3}$ hexane solution was more destroyed in Catalyst-II than in Catalyst-I. In other words, Catalyst-II may have slightly better catalytic activity than Catalyst-I after the alkylation step.

When $\mathrm{Al}\left({ }^{i} \mathrm{Bu}\right)_{2} \mathrm{Cl}$ was further added into the mixed solution of alkylaluminum and $\mathrm{Nd}(\text { vers })_{3}$, the chlorination reaction was performed. For Catalyst-II with the mole ratio of $\mathrm{Al}\left({ }^{i} \mathrm{Bu}\right)_{2}$ $\mathrm{Cl}: \mathrm{AlEt}_{3}: \mathrm{Nd}(\text { vers })_{3}$ being $3: 10: 1$, there are about $4.5 \mathrm{Nd}-\mathrm{C}$ bondings at $2.58 \AA$ and $3.0 \mathrm{Nd}-\mathrm{Cl}$ bondings at $2.88 \AA$. In addition, it can be also found that $2.2 \mathrm{Nd}-\mathrm{Al}$ atom-pairs locate at $3.15 \AA$.
For Catalyst-I with the mole ratio of $\mathrm{Al}\left({ }^{i} \mathrm{Bu}\right)_{2} \mathrm{Cl}: \mathrm{Al}\left({ }^{i} \mathrm{Bu}\right)_{3^{-}}$ : $\mathrm{Nd}$ (vers) $)_{3}$ being $3: 10: 1$, there are about $3.4 \mathrm{Nd}-\mathrm{C}$ bondings at $2.58 \AA$ and $2.2 \mathrm{Nd}-\mathrm{Cl}$ bondings at $2.87 \AA$. In addition, it can be also found that $1.9 \mathrm{Nd}-\mathrm{Al}$ atom-pairs locate at 3.14 A. Roughly, the chlorination steps are very similar in both cases. The residual $\mathrm{Nd}-\mathrm{O}$ bondings in alkylation step have been completely replaced by $\mathrm{Nd}-\mathrm{Cl}$ bondings and the $\mathrm{Nd}-\mathrm{C}$ bondings keep almost unchanged. Relatively speaking, the coordination number around Nd center is less in Catalyst-I than in Catalyst-II, which means that the residual oligomeric structure after the alkylation step was destroyed more seriously in Catalyst-I than in CatalystII. In other words, Catalyst-I has better catalytic activity than Catalyst-II after the chlorination step. Obviously, the alkylation step and the chlorination step have slightly different effects on different Nd-based ternary catalysts. Perhaps it was these slight differences that lead the slight change of catalytic activity among different Nd-based ternary catalysts. By comparing the structures at different activation steps, it can be concluded that the Ndbased ternary catalysts with different alkylaluminum component indeed present a similar structure evolution in the alkylation and chlorination processes as expected, their main difference comes from the slightly different coordination number around the Nd centers as well as the slightly different activation effect in alkylation and chlorination steps.

\subsection{Theoretical calculation}

As discussed above, in situ XAFS measurements identify that the $\mathrm{Nd}-\mathrm{O}$ bondings in $\mathrm{Nd}$ (vers) ${ }_{3}$ hexane solution have been partially replaced by the $\mathrm{Nd}-\mathrm{C}$ bondings when the alkylaluminum was added into the $\mathrm{Nd}$ (vers) ${ }_{3}$ hexane solution in the alkylation step. However, this replacement of $\mathrm{Nd}-\mathrm{O}$ bondings by $\mathrm{Nd}-\mathrm{C}$ bondings obtained by XAFS technique is controversial because of the approximate electron scatterings between oxygen and carbon atoms. In other words, it is not so credible that XAFS technique can be used to distinguish the bondings between $\mathrm{Nd}-\mathrm{O}$ and $\mathrm{Nd}-$ C. To ensure the reliability of the obtained $\mathrm{Nd}-\mathrm{O}$ and $\mathrm{Nd}-\mathrm{C}$ bondings with XAFS technique, theoretical calculation is used to the alkylation process of $\mathrm{Nd}(\text { vers })_{3}$ after $\mathrm{AlEt}_{3}$ mixing with the $\mathrm{Nd}(\text { vers })_{3}$ hexane solution.

3.2.1 Computational details. In the theoretical calculations, the hybrid exchange-correlation functional $\mathrm{B}^{2} \mathrm{LYP}^{\mathbf{4 4 , 4 5}}$ with the Gaussian 09 program ${ }^{46}$ were applied to insight into the binding sites and coordination modes between $\mathrm{Nd}(\text { vers })_{3}$ and $\mathrm{AlEt}_{3}$. For Nd atom, the quasi-relativistic small-core pseudopotential ECP48MWB and associated ECP60MWB valence basis sets was used, ${ }^{47}$ while 6-31G(d) basis set was applied for the other light atoms $\mathrm{H}, \mathrm{C}$ and $\mathrm{O}$. To simulate the experimental condition, all the structures were optimized using the Solvation Model based on Density (SMD model) ${ }^{48}$ in hexane solution $(\varepsilon=$ 1.8819). Therefore, all structure optimizations calculations were performed at the B3LYP/6-31G(d)/SMD/RECP level of theory in hexane solution. All the optimization structures are confirmed to be local minima without imaginary frequency.

Computational chemistry could provide a reliable method in understanding the coordination modes of ligands with f-block elements. ${ }^{49-51}$ In order to identify possible coordination modes 
and detailed coordination structures, four Nd complexes A-D at the B3LYP/6-31G(d)/SMD/RECP level of theory in hexane solution were optimized as shown in Fig. 1. The complexes A-D represent the mixture composing $\mathrm{Nd}(\text { vers })_{3}$ and $\mathrm{AlEt}_{3}$ with different $\mathrm{Al}: \mathrm{Nd}$ ratios (beginning from $0: 1$ ). The predicted $\mathrm{Nd}-\mathrm{O}$ and $\mathrm{Nd}-\mathrm{C}$ bond distances of the four $\mathrm{Nd}$ complexes are listed in Table $\mathrm{S} 2$ of the ESI $\dagger$ and the average bond distances are also provided in Fig. 1. It is clearly seen that Nd atom coordinates with ten oxygen atoms from five bidentate carboxyl groups in complex $\mathbf{A}$ and the ten $\mathrm{Nd}-\mathrm{O}$ bond distances are divided into two equal groups with the average $\mathrm{Nd}-\mathrm{O}$ bond distance of 2.397 and $2.571 \AA$, respectively, which are excellent agreement with the XAFS results (2.39 and 2.54 $\AA$ ) for the pure $\mathrm{Nd}$ (vers) $)_{3}$ hexane solution as shown in the ESI. $\uparrow$ This result indicates that the level of theory we used here is favorable for $\mathrm{Nd}$ complexes. Complex $\mathbf{B}$ with three bidentate carboxyl groups contains $6 \mathrm{Nd}-\mathrm{O}$ bonds and $2 \mathrm{Nd}-\mathrm{C}$ bonds with the corresponding average bond distance of 2.468 and $2.572 \AA$, respectively. Unlike complex B, there are one bidentate and two mono-dentate carboxyl groups surrounding the central $\mathrm{Nd}$ atom in complex $\mathbf{C}$, which form 4 $\mathrm{Nd}-\mathrm{O}$ bonds and three $\mathrm{Nd}-\mathrm{C}$ bonds. The average $\mathrm{Nd}-\mathrm{O}$ and $\mathrm{Nd}-$ $\mathrm{C}$ bond distances in complex $\mathrm{C}$ is 2.408 and $2.580 \AA$, respectively, which are comparable with the XAFS data (2.38 and 2.58 A) in Sample A1 or A2. As for complex D, there are only two mono-dentate carboxyl groups, the average $\mathrm{Nd}-\mathrm{O}$ bond distance for the $2 \mathrm{Nd}-\mathrm{O}$ bonds is $2.343 \AA$, and the average $\mathrm{Nd}-\mathrm{C}$ bond distance for the $4 \mathrm{Nd}-\mathrm{C}$ bonds is $2.751 \AA$. The coordination numbers of $\mathrm{Nd}$ in complex $\mathbf{D}$ are consistent with the XAFS result in Sample A3. These theoretical calculations demonstrate that the coordination number of $\mathrm{Nd}-\mathrm{O}$ decreases from 10 in complex $\mathbf{A}$ to 2 in complex $\mathbf{D}$, while the corresponding coordination number of $\mathrm{Nd}-\mathrm{C}$ increase from 0 to 4 . Indeed, the pure $\mathrm{Nd}-\mathrm{O}$ bonds in $\mathrm{Nd}$ (vers) $)_{3}$ hexane solution can be replaced by the mixture of $\mathrm{Nd}-\mathrm{O}$ and $\mathrm{Nd}-\mathrm{C}$ bonds with the adding $\mathrm{AlEt}_{3}$ into the $\mathrm{Nd}$ (vers) ${ }_{3}$ hexane solution. At the same time, the coordination

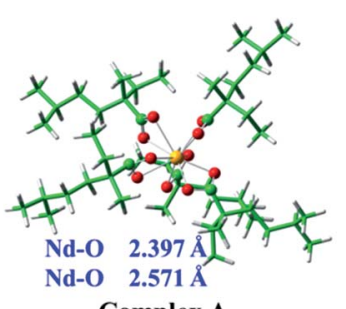

Complex A

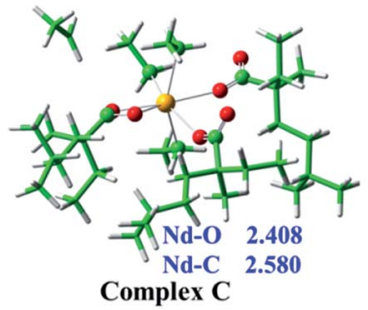

Fig. 1 Structures of the complexes optimized at the B3LYP/6-31G(d)/ $\mathrm{SMD} / \mathrm{RECP}$ level of theory in hexane solution. Average $\mathrm{Nd}-\mathrm{O}$ and $\mathrm{Nd}-$ $C$ bond distances $(\AA)$ are provided. Orange, red, green and white colors denote $\mathrm{Nd}, \mathrm{O}, \mathrm{C}, \mathrm{H}$ atoms, respectively. mode of the carboxyl group changes from bidentate fashion to mono-dentate mode. In addition, the highest single occupied molecular orbital (SOMO) for the four complexes are also calculated and displayed in Fig. S4 of the ESI, $\uparrow$ it is apparent that the electron density mainly localizes on the $\mathrm{Nd}$ atom and one carboxyl group.

To insight further into the change of coordination number and coordination sites, the binding energies $\left(E_{\text {binding }}\right)$ of complexes A-D were calculated according to eqn (1):

$$
\begin{gathered}
\mathrm{Nd}(\mathrm{III})+m \text { ver }+n \mathrm{Et} \rightarrow \mathrm{Nd}(\mathrm{III})(\mathrm{ver})_{m}(\mathrm{Et})_{n} \\
E_{\text {binding }}=E_{\mathrm{Nd}(\mathrm{III})(\mathrm{ver}) m(\mathrm{Et}) n}-n E_{\mathrm{Et}}-m E_{\mathrm{ver}}-E_{\mathrm{Nd}(\mathrm{III})}
\end{gathered}
$$

Here, the electronic energies $(E)$ of the products and reactants were used, the binding energies were calculated as listed in Table S2 of the ESI. $\dagger$ These calculated binding energies indicate that the complexes are more easily formed accompanying with the Et ligand addition, except for complex $\mathbf{C}$. The reason maybe there is one free Et ligand in complex $\mathbf{C}$. The trend of the absolute binding energies of the other three complexes follows the order $\mathbf{A}<\mathbf{B}<\mathbf{D}$, which reveal that the more Nd-C bonds form, and the more Nd-O bonds disappear. In other words, more $\mathrm{Nd}-\mathrm{O}$ bonds can be displaced by $\mathrm{Nd}-\mathrm{C}$ bonds with more $\mathrm{AlEt}_{3}$ adding into the $\mathrm{Nd}$ (vers) ${ }_{3}$ hexane solution. It can be seen that the theoretical calculations support the XAFS experimental observations. Therefore, it can be concluded that the pure $\mathrm{Nd}-\mathrm{O}$ bonds in the $\mathrm{Nd}(\text { vers })_{3}$ hexane solution can be replaced into the mixture of $\mathrm{Nd}-\mathrm{O}$ and $\mathrm{Nd}-\mathrm{C}$ bonds with the adding $\mathrm{AlEt}_{3}$ into the $\mathrm{Nd}(\text { vers })_{3}$ hexane solution.

\subsection{Polymerization process}

As we know, the structure around Nd center during the polymerization of IP and the structure change in the polymerization process of IP with the assistance of different Nd-based ternary catalysts are still unclear. In this paper, four Nd-based ternary catalysts with different alkylaluminum components $\left\{\mathrm{AlEt}_{3}\right.$, $\mathrm{Al}\left({ }^{n} \mathrm{Oct}\right)_{3}, \mathrm{Al}\left({ }^{i} \mathrm{Bu}\right)_{3}$, and $\left.\mathrm{Al}\left({ }^{i} \mathrm{Bu}\right)_{2} \mathrm{H}\right\}$ were used in the polymerization processes of IP, respectively, which are denoted as Sample B1, B2, B3 and B4. In situ XAFS technique was used to extract the local atomic structures around Nd centers. The original X-ray absorption spectra for the four samples are provided as Fig. S5 in the ESI. $\uparrow$ After normalizing and background removal, the corresponding Fourier-transform (FT) spectra without phase-shift correction are compared and shown in Fig. 2. It can be found that the main coordination peak is split into two distinct coordination sub-peaks for all the four samples. One sub-peak has almost the same peak position $(\sim 2.4 \AA)$ with the single peak in Sample A4 without IP. Another sub-peak appears at smaller position at about $1.8 \AA$. This unexpected change demonstrates that the local environments around $\mathrm{Nd}$ centers have obvious changes when the Nd-based ternary catalysts are used for the polymerization reaction of IP. For Samples B1-B3, the lower- $R$ sub-peaks have obviously lower magnitude than the higher- $R$ ones, but the two sub-peaks have quite approximate magnitudes for Sample B4. To extract the quantitative structural parameters, the two sub-peaks in the region from 1.38 to $2.88 \AA$ 


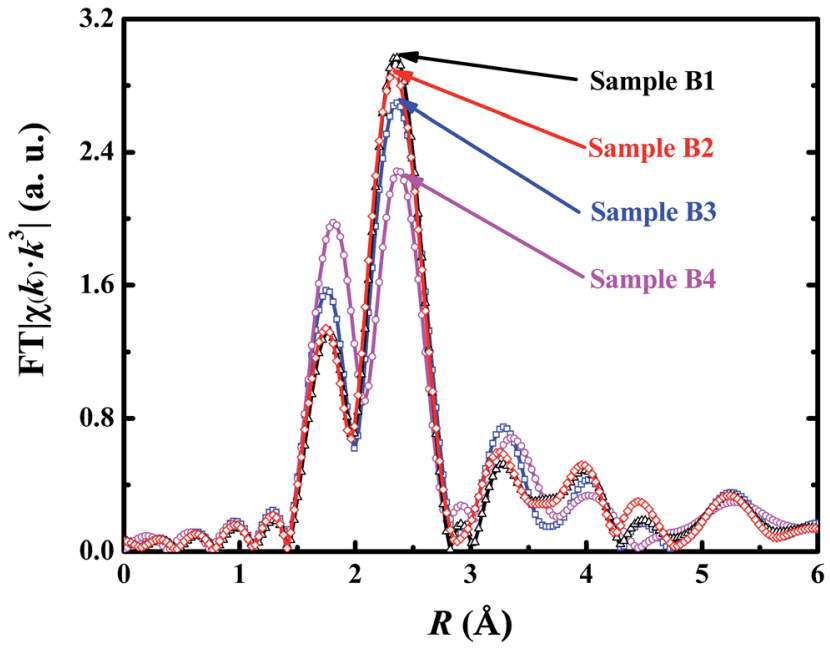

Fig. 2 Fourier transform spectra of $\mathrm{Nd} \mathrm{L}_{111}$-edge EXAFS data in the polymerization process of IP with the assistance of four $\mathrm{Nd}$-based ternary catalysts. The alkylaluminum components in the four catalysts are $\mathrm{AlEt}_{3}$ (Sample B1), $\mathrm{Al}\left({ }^{n} \mathrm{Oct}\right)_{3}$ (Sample B2), $\mathrm{Al}\left({ }^{i} \mathrm{Bu}\right)_{3}$ (Sample B3), and $\mathrm{Al}\left({ }^{i} \mathrm{Bu}\right)_{2} \mathrm{H}$ (Sample B4), respectively.

of the FT spectra were isolated and inverse Fourier transformed into $k$-space with $k^{3}$-weight to get the near-neighbor extended Xray absorption fine structure (EXAFS) signals. After testing various fitting strategies, three sub-shells including $\mathrm{Nd}-\mathrm{C}$, Nd$\mathrm{Cl}$ and $\mathrm{Nd}-\mathrm{Al}$ had to be used for the EXAFS fittings. The $R$-space and $k$-space fitting curves are shown in Fig. 3. The corresponding fitting parameters are summarized in Table 2.

By comparing the fitting parameters of Sample B1 with the ones of Sample A4 which are given in Table S1 of the ESI, $\dagger$ it can be found that the coordination numbers around $\mathrm{Nd}$ center were further decreased after IP was mixed with the Nd-based ternary catalyst consisting of $\mathrm{Nd}(\text { vers })_{3}, \mathrm{AlEt}_{3}$, and $\mathrm{Al}\left({ }^{i} \mathrm{Bu}\right)_{2} \mathrm{Cl}$. The $\mathrm{Nd}-\mathrm{C}$ coordination number decreased from 4.5 to 1.4 , the $\mathrm{Nd}-\mathrm{Cl}$ coordination number decreased from 3.0 to 2.3 , and the $\mathrm{Nd}-\mathrm{Al}$ coordination number decreased from 2.2 to 1.3 . This result

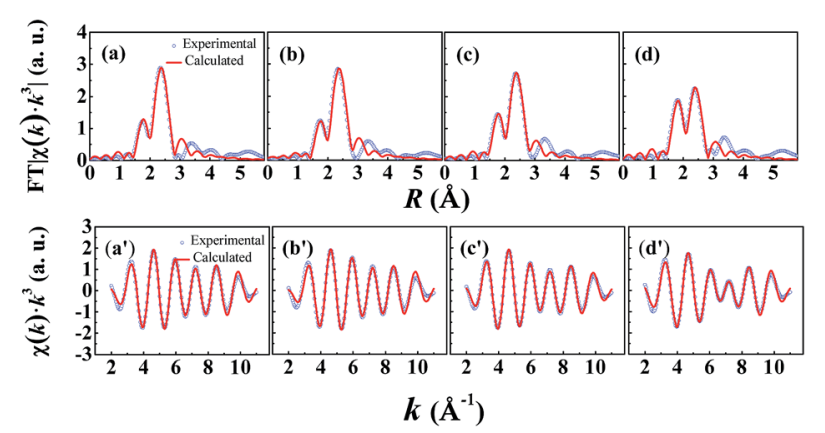

Fig. 3 EXAFS fitting curves in $R$-space (upper panel) and $k$-space (lower panel) for the $\mathrm{Nd} \mathrm{L}_{1 I I}$-edge EXAFS data during the polymerization of IP with the assistance of four different $\mathrm{Nd}$-based ternary catalysts. In the four catalysts, the alkylaluminum component is, respectively, $\mathrm{AlEt}_{3}\left(\right.$ Sample B1, a, $\left.\left.\mathrm{a}^{\prime}\right), \mathrm{Al}{ }^{\mathrm{n}} \mathrm{Oct}\right)_{3}$ (Sample B2, b, b'), $\left.\mathrm{Al}^{(}{ }^{i} \mathrm{Bu}\right)_{3}$ (Sample B3, C, $\mathrm{C}^{\prime}$ ), and $\mathrm{Al}^{\prime}\left({ }^{\mathrm{B} u}\right)_{2} \mathrm{H}$ (Sample B4, d, $\mathrm{d}^{\prime}$ ). Open circles represent the experimental values and solid lines represent the fitting curves.
Table 2 Nd LIII-edge EXAFS fitting parameters for the Samples B1-B4. Here, $N$ is the coordination number, $R$ is the interatomic distance, and $\sigma^{2}$ is the Debye-Waller factor

\begin{tabular}{lllll}
\hline Sample & Bond & $N$ & $R(\AA)$ & $\sigma^{2}\left(\AA^{2}\right)$ \\
\hline \multirow{3}{*}{ B1 } & Nd-C & 1.4 & 2.42 & 0.0052 \\
& Nd-Cl & 2.3 & 2.85 & 0.0044 \\
& Nd-Al & 1.3 & 3.13 & 0.0030 \\
B2 & Nd-C & 1.1 & 2.41 & 0.0036 \\
& Nd-Cl & 2.2 & 2.85 & 0.0044 \\
& Nd-Al & 1.3 & 3.13 & 0.0023 \\
B3 & Nd-C & 1.7 & 2.41 & 0.0056 \\
& Nd-Cl & 2.2 & 2.85 & 0.0050 \\
& Nd-Al & 1.4 & 3.13 & 0.0035 \\
B4 & Nd-C & 2.0 & 2.42 & 0.0052 \\
& Nd-Cl & 2.0 & 2.85 & 0.0054 \\
& Nd-Al & 1.0 & 3.13 & 0.0037
\end{tabular}

indicates that there are only about 1-2 ethyl or IP molecules, and $2 \mathrm{Cl}$ atoms or $\mathrm{Al}\left({ }^{i} \mathrm{Bu}\right)_{2} \mathrm{Cl}$ ligands bonded to the $\mathrm{Nd}$ centers during the polymerization of IP. In addition, the coordination distance of $\mathrm{Nd}-\mathrm{C}$ bonds (or Nd-Cl bonds) has a contraction from 2.58 to $2.42 \AA$ (or from 2.88 to $2.85 \AA$ ) due to the decrease of total coordination number, which could imply that the IP molecules have replaced the alkyl ligands bonded directly to the Nd center. The second near-neighbor (Nd-Cl-Al) distance also shows a slight decrease from 3.15 to $3.13 \AA$. The distance difference between $\mathrm{Nd}-\mathrm{Cl}$ and $\mathrm{Nd}-\mathrm{C}$ bonds is about $0.43 \AA$, which is obviously larger than $0.3 \AA$ in Sample A4. It was the increase of distance difference between $\mathrm{Nd}-\mathrm{Cl}$ and $\mathrm{Nd}-\mathrm{C}$ bonds that leads the split of the main coordination peak when IP was mixed with the Nd-based ternary catalyst. Sabirov et al. $^{28}$ carried out quantum chemical calculations for models of the active centers involved in butadiene polymerization in the presence of $\mathrm{Nd}-\mathrm{Al}$ catalytic systems. Two shorter distances ( 2.0 and $2.4 \AA$ ) between the crotyl group and the $\mathrm{Nd}$ atom are obtained. Such a Nd-C distance of $2.4 \AA$ is comparable to the result in this paper.

From Table 2 and Fig. 2, it can be found that Sample B1 and B2 have almost the same fitting parameters and FT spectral features. Both have approximately one $\mathrm{Nd}-\mathrm{C}$ bond at $2.42 \AA$ and two $\mathrm{Nd}-\mathrm{Cl}$ bonds at $2.85 \AA$. From Sample B1, B2, to B3, and then to $\mathrm{B} 4$, the magnitude of lower- $R$ peak increase gradually and the magnitude of higher- $R$ peak decrease gradually. Accordingly, the $\mathrm{Nd}-\mathrm{C}$ coordination number has an increase tendency, while the $\mathrm{Nd}-\mathrm{Cl}$ coordination number has a decrease tendency, but the $\mathrm{Nd}-\mathrm{C}$ and $\mathrm{Nd}-\mathrm{Cl}$ bond distances are approximately unchanged. It tells us clearly that the lower- $R$ peak is corresponding to the contribution of Nd-C bonds, while the higher- $R$ peak is corresponding to the contribution of $\mathrm{Nd}-\mathrm{Cl}$ bonds. The contribution from the second near-neighbor Nd-Cl-Al should also be involved in the high- $R$ coordination peak. By comparing the fitting parameters for Sample B1-B4, the fine distinction between the four samples has been determined although their rough structures are quite similar.

The fine structure distinction around Nd centers among the four samples can be attributed to the difference of the 
alkylaluminum components in the Nd-based ternary catalysts. In Samples B1 and B2, the carbon chains in $\mathrm{AlEt}_{3}$ and $\mathrm{Al}\left({ }^{n} \mathrm{Oct}\right)_{3}$ are all linear chains. But in Sample B3 and B4, the alkylaluminum component $\mathrm{Al}\left({ }^{i} \mathrm{Bu}\right)_{3}$ and $\mathrm{Al}\left({ }^{i} \mathrm{Bu}\right)_{2} \mathrm{H}$ all have the side chains. Our results demonstrate that the Nd-based ternary catalysts with line-chain alkylaluminum have relatively less $\mathrm{Nd}-\mathrm{C}$ coordination number in the polymerization process of IP, while these catalysts with side-chain alkylaluminum have relatively more Nd-C coordination number. Perhaps, the isobutyl have partial contribution to promote the $\mathrm{Nd}-\mathrm{C}$ coordination. Generally speaking, the replacement of alkylaluminum in the Nd-based ternary catalysts will lead a fine structure difference around Nd centers because of the different alkyl configuration when the Nd-based ternary catalysts are used to catalyze the polymerization of IP. We believe that these fine differences will slightly influence on the polymerization performance of IP. The highest number of $\mathrm{Nd}-\mathrm{C}$ coordination in Sample $\mathrm{B} 4$, i.e., $\mathrm{Al}\left({ }^{i} \mathrm{Bu}\right)_{2} \mathrm{H}$ system supports the research by Friebe ${ }^{19}$ that the easier transfer of hydride from $\mathrm{Al}\left({ }^{i} \mathrm{Bu}\right)_{2} \mathrm{H}$ promotes more intense chain transfer for producing polymer with lowest molar mass.

\subsection{Catalytic mechanism}

The catalytic mechanism of Nd-based ternary catalysts in the polymerization reaction of synthetic rubber is a highly interesting issue. Due to the complexity of the sample systems and the difficulty in the real-time structural characterization, the structural information of the catalytic active site in the polymerization reaction is quite scarce. Up to now, the catalytic mechanism of Nd-based ternary catalysts is still ambiguous. Based on the structure analysis of $\mathrm{Nd}$ precursor by matrixassisted laser desorption ionization time-of-flight (MALDITOF) mass spectrum, Kwag' ${ }^{17}$ considered that the dissociated monomeric structure of $\mathrm{Nd}(\text { vers })_{3} \cdot$ (neodecanoic acid) is the reason to have a higher activity, and a catalyst activation and propagation mechanism was depicted. Many researches ${ }^{23,29-32}$ speculated that the insertion and propagation of polymer chain between the $\mathrm{Nd}$ center and the alkyl group facilitate the polymerization reaction, which is because of the high number of coordination possibilities at the $\mathrm{Nd}$ atom through the vacancies on its " $4 \mathrm{f}$ " orbitals and the unstable $\mathrm{Nd}-\mathrm{C}$ bond in the catalyst being replaced by the much more stable $\pi$ complex through reaction. Fischbach et al. ${ }^{26}$ investigated the dynamic behavior of the tetraalkylaluminate ligand and the coordination features of heteroleptic mono- and bis(tetraalkylaluminate) complexes through variable-temperature NMR studies and X-ray crystallographic analyses. They modified the allyl insertion mechanism of isoprene polymerization by underlining the ease of polymer chain transfer via Ln-Al heterobimetallic complexes in Ziegler-type catalyst.

To insight into the catalytic mechanisms of Nd-based ternary catalysts in synthetic rubber, in situ XAFS has been used to extract the local atomic structures around $\mathrm{Nd}$ center in the polymerization process of IP in above section. It has been confirmed that the main catalyst $\mathrm{Nd}(\text { vers })_{3}$ in hexane solution still maintains a certain oligomeric structure even if $\mathrm{Nd}(\text { vers })_{3}$ has been partially alkylated by adding alkylaluminum into the solution. This alkylation process can only activate its catalytic activity partially. When the cocatalyst $\mathrm{Al}\left({ }^{i} \mathrm{Bu}\right)_{2} \mathrm{Cl}$ was further added into the partially-alkylated $\mathrm{Nd}(\text { vers })_{3}$ hexane solution, the residual $\mathrm{Nd}-\mathrm{O}$ bonds were completely removed by a chlorination processes. In this moment, the active Nd centers were only bonded to $\mathrm{C}$ atoms from alkyl and the $\mathrm{Cl}$ atoms from $\mathrm{Al}\left({ }^{i} \mathrm{Bu}\right)_{2} \mathrm{Cl}$. The original oligomeric structure of $\mathrm{Nd}(\text { vers })_{3}$ in hexane solution has been completely dissociated, thus the Nd-based ternary catalysts show highly activity. We notice that there are still 4-5 C atoms at $2.58 \AA$ and about $3 \mathrm{Cl}$ atoms at $2.88 \AA$ coordinated to $\mathrm{Nd}$ centers as in Sample A4. It is interesting that the Nd coordination structure shows again a larger change when the Ndbased ternary catalysts were used for the polymerization of IP. There are only 1-2 $\mathrm{C}$ atoms and about $2 \mathrm{Cl}$ atoms located at the neighborhood of $\mathrm{Nd}$ centers, showing a monomer state of $\mathrm{Nd}$ active center. Specially, the $\mathrm{Nd}-\mathrm{C}$ bond distance has been drastically contracted to $2.42 \AA$. These in situ structural informations reflect the real change of coordination structure around Nd center. Under the assistance of the Nd-based ternary catalysts, the polymerization reaction of IP would occur at the neighborhood of the Nd center. In other words, the nomadic IP molecules were gradually polymerized together through the interaction with the $\mathrm{Nd}$ center. Therefore, the $\mathrm{C}$ atoms from the IP molecules will dynamically contribute to the $\mathrm{Nd}-\mathrm{C}$ coordination. Due to only 1-2 C atoms were bonded to Nd center, we believe that the original $4-5$ alkyls bonded to $\mathrm{Nd}$ center in the pure Nd-based ternary catalyst have been desorbed from the $\mathrm{Nd}$ center in the presence of IP molecules. Evidently, the bonding between $\mathrm{Nd}$ and the alkyl is not so strong as compared with the interaction between $\mathrm{Nd}$ and the IP The dynamic bonding between $\mathrm{Nd}$ center and the $\mathrm{C}$ atoms from IP molecule is the driving force to polymerize the IP molecules.

Based on the in situ XAFS experiments, the extracted structure parameters around Nd center support strongly the catalyst activation and propagation mechanism of previous researches. ${ }^{23,29-32}$ $\mathrm{Kwag}^{17}$ also illustrate the polymerization process of $\mathrm{NDH}$, i.e., $\mathrm{Nd}(\mathrm{OOCR})_{3} \cdot(\mathrm{HOOCR})$, there is no oxygen bonded to the $\mathrm{Nd}$ center after chlorination and the butadiene polymerization should be changed into isoprene polymerization, which are slightly different with our result. The catalytic mechanism for IP polymerization can be speculated as follows. First, due to the decrease of coordination number, the highly-opened Nd centers present a highly catalytic activity in the presence. When nomadic IP monomers move to the neighborhood of Nd center, the high state-density of f-electrons in Nd center induces the redistribution of the electrons in the IP monomer. As a consequence, the IP monomer interacts with the Nd centers through an intermediate complex with $\pi$ bond. In this case, this IP monomer is activated to have a tendency of polymerization with other IP monomer. When another IP monomer moves to the Nd center, the new IP monomer is activated again by the $\mathrm{Nd}$ center. Thus the two activated IP monomers are polymerized together to form an IP dimer. Due to the new-formed IP dimer is still located at the neighborhood of the Nd center, the IP dimer interacts again with and is activated by the Nd centers, forming a new intermediate complex with $\pi$ bond. With new IP monomer moves to the 


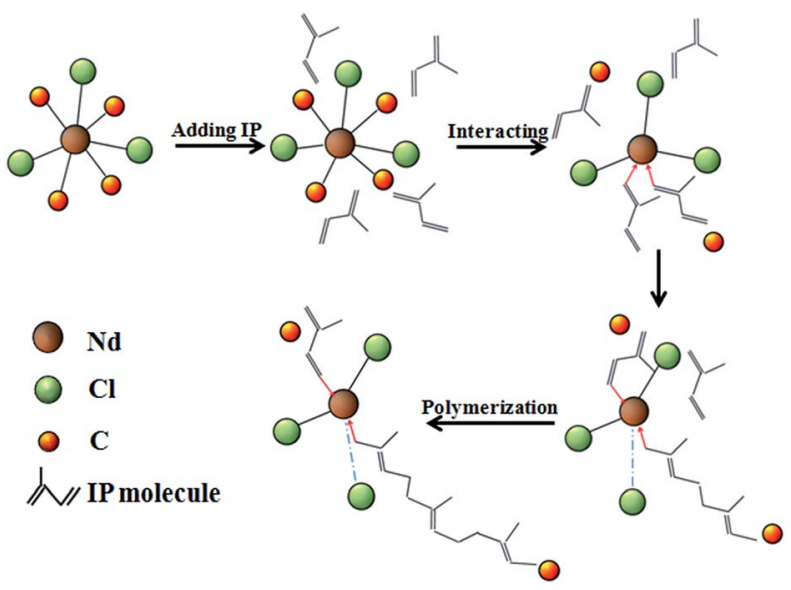

Fig. 4 A schematic map about the polymerization process of IP molecules.

neighborhood of the Nd center again, the newest IP monomer is polymerized onto the IP dimer. In this polymerization process, the new-coming IP monomer behaves as an inserter between the Nd-center and the IP multimer. The above polymerization is repeatedly performed until the IP monomers are exhausted or the as-formed IP multimers are far away from each other. During the polymerization process, the IP are dynamically bonded to the Nd centers. Averagely, there are 1-2 C atoms from IP monomers or polymer connecting simultaneously to one $\mathrm{Nd}$ center. The $\mathrm{Cl}$ atoms are always bonded to the Nd centers in the polymerization process of IP, which play a role to activate and stabilize the catalytic activity of $\mathrm{Nd}$ centers. A schematic map for the IP polymerization mechanism is shown in Fig. 4.

\section{Conclusions}

In situ XAFS technique has been used to study the Nd-based ternary catalysts as well as the corresponding polymerization processes of IP. The conclusions can be summarized as follows:

(1) For the Nd-based ternary catalysts containing $\mathrm{Nd}(\text { vers })_{3}$, alkylaluminum, and $\mathrm{Al}\left({ }^{i} \mathrm{Bu}\right)_{2} \mathrm{Cl}$, the structural evolutions around the $\mathrm{Nd}$ center are similar with the change of alkylaluminum component. The two-shell $\mathrm{Nd}-\mathrm{O}$ coordination in $\mathrm{Nd}$ (vers) $)_{3}$ hexane solution are replaced to about $1-2 \mathrm{Nd}-\mathrm{O}$ bonds and $4 \mathrm{Nd}-\mathrm{C}$ bonds in the alkylation process with the $\mathrm{Al}: \mathrm{Nd}$ ratio of $10: 1$, and are further replaced to about $4 \mathrm{Nd}-\mathrm{C}$ bonds and $3 \mathrm{Nd}-\mathrm{Cl}$ bonds in the chlorination process with $\mathrm{Cl}: \mathrm{Al}: \mathrm{Nd}$ ratio of $3: 10: 1$.

(2) In situ XAFS experiments demonstrate that the $\mathrm{Nd}-\mathrm{O}$ coordination number decreases from about 5 to 1.5 , and the $\mathrm{Nd}-\mathrm{C}$ coordination number keeps almost unchanged with the increase of $\mathrm{Al}: \mathrm{Nd}$ ratio from $1: 1$ to $10: 1$ in the alkylaluminum process. Theoretical calculation verifies the reasonability of the substitution between $\mathrm{Nd}-\mathrm{O}$ and $\mathrm{Nd}-\mathrm{C}$ bonds.

(3) The local atom structures around $\mathrm{Nd}$ center are similar with the alteration of the alkylaluminum in the polymerization process of IP with the assistance of four different Nd-based ternary catalysts. The $\mathrm{Nd}$ center is in a monomer state with highly catalytic activity in the presence of IP.
(4) During the polymerization processes of IP, there are about $2 \mathrm{Nd}-\mathrm{Cl}$ bonds at $2.85 \AA$. The average number of $\mathrm{Nd}-\mathrm{C}$ bonds is $1-2$ at about $2.42 \AA$. This highly-opened structure activates greatly the catalytic activity of the $\mathrm{Nd}$-based ternary catalysts. A catalytic mechanism for the polymerization process of IP with the assistance of the Nd-based ternary catalysts has been depicted in this paper.

\section{Acknowledgements}

This work was supported by National Natural Science Foundation (Nos. U1232203, U1432104, 11405199, 21374077, 11305198, U1332107) of China.

\section{References}

1 Y. Pan, T. Xu, G.-W. Yang, K. Jin and X.-B. Lu, Bis (oxazolinyl) phenyl-Ligated Rare-Earth-Metal Complexes: Highly Regioselective Catalysts for cis-1,4-Polymerization of Isoprene, Inorg. Chem., 2013, 52(6), 2802-2808.

2 H. Liu, J. He, Z. Liu, Z. Lin, G. Du, S. Zhang and X. Li, QuasiLiving trans-1, 4-Polymerization of Isoprene by Cationic Rare Earth Metal Alkyl Species Bearing a Chiral (S, S)-Bis (oxazolinylphenyl) amido Ligand, Macromolecules, 2013, 46(9), 3257-3265.

3 A. Fischbach, C. Meermann, G. Eickerling, W. Scherer and R. Anwander, Discrete lanthanide aryl (alk) oxide trimethylaluminum adducts as isoprene polymerization catalysts, Macromolecules, 2006, 39(20), 6811-6816.

4 K. Satoh, M. Kamigaito and M. Sawamoto, Lanthanide Triflates-Mediated Emulsion Cationic Polymerization of pAlkoxystyrenes in Aqueous Media 1, Macromolecules, 2000, 33(13), 4660-4666.

$5 \mathrm{M}$. Oshimura and A. Takasu, Controlled ring-opening polymerization of $\varepsilon$-caprolactone catalyzed by rare-earth perfluoroalkanesulfonates and perfluoroalkanesulfonimides, Macromolecules, 2010, 43(5), 2283-2290.

6 T. J. Woodman, Y. Sarazin, G. Fink, K. Hauschild and M. Bochmann, Heterogenized "Ligand-Free" Lanthanide Catalysts for the Homo-and Copolymerization of Ethylene and 1, 3-Butadiene, Macromolecules, 2005, 38(8), 3060-3067.

7 T. Chenal and M. Visseaux, Combining Polyethylene CCG and Stereoregular Isoprene Polymerization: First Synthesis of Poly (ethylene)-b-(trans-isoprene) by Neodymium Catalyzed Sequenced Copolymerization, Macromolecules, 2012, 45(14), 5718-5727.

$8 \mathrm{~J}$. Ling, Z. Shen and Q. Huang, Novel single rare earth aryloxide initiators for ring-opening polymerization of 2, 2dimethyltrimethylene carbonate, Macromolecules, 2001, 34(22), 7613-7616.

9 L. Annunziata, A.-S. Rodrigues, E. Kirillov, Y. Sarazin, J. Okuda, L. Perrin, L. Maron and J.-F. Carpentier, Isoselective Styrene Polymerization Catalyzed by ansa-Bis (indenyl) Allyl Rare Earth Complexes. Stereochemical and Mechanistic Aspects, Macromolecules, 2011, 44(9), 33123322 . 
10 W. J. Evans, D. G. Giarikos and J. W. Ziller, Lanthanide carboxylate precursors for diene polymerization catalysis: Syntheses, structures, and reactivity with Et2AlCl, Organometallics, 2001, 20(26), 5751-5758.

11 S. Kaita, M. Yamanaka, A. C. Horiuchi and Y. Wakatsuki, Butadiene polymerization catalyzed by lanthanide metallocene-alkylaluminum complexes with cocatalysts: Metal-dependent control of 1, 4-cis/trans stereoselectivity and molecular weight, Macromolecules, 2006, 39(4), 13591363.

$12 \mathrm{~W}$. Dong and T. Masuda, Homogeneous neodymium isopropoxide/modified methyl- aluminoxane catalyst for isoprene polymerization, Polymer, 2003, 44(5), 1561-1567.

13 F. Bonnet, M. Visseaux, A. Pereira and D. Barbier-Baudry, Highly trans-stereospecific isoprene polymerization by neodymium borohydrido catalysts, Macromolecules, 2005, 38(8), 3162-3169.

14 D. J. Wilson and D. K. Jenkins, Butadiene polymerisation using ternary neodymium-based catalyst systems, Polym. Bull., 1992, 27(4), 407-411.

15 L. Friebe, O. Nuyken, H. Windisch and W. Obrecht, Polymerization of 1, 3-Butadiene Initiated by Neodymium Versatate/Diisobutylaluminium Hydride/Ethylaluminium Sesquichloride: Kinetics and Conclusions About the Reaction Mechanism, Macromol. Chem. Phys., 2002, 203(8), 1055-1064.

16 G. Kwag, P. Kim, S. Han and H. Choi, Ultra high cis polybutadiene by monomeric neodymium catalyst and its tensile and dynamic properties, Polymer, 2005, 46(11), 3782-3788.

17 G. Kwag, A highly reactive and monomeric neodymium catalyst, Macromolecules, 2002, 35(13), 4875-4879.

18 G. Kwag, H. Lee and S. Kim, First in-situ observation of pseudoliving character and active site of Nd-based catalyst for 1, 3-butadiene polymerization using synchrotron X-ray absorption and UV-visible spectroscopies, Macromolecules, 2001, 34(16), 5367-5369.

19 L. Friebe, H. Windisch, O. Nuyken and W. Obrecht, Polymerization of 1, 3-butadiene initiated by neodymium versatate/triisobutylaluminum/ethylaluminum sesquichloride: Impact of the alkylaluminum cocatalyst component, J. Macromol. Sci., Part A: Pure Appl.Chem., 2004, 41(3), 245-256.

20 L. Friebe, O. Nuyken and W. Obrecht, Neodymium-based Ziegler/Natta catalysts and their application in diene polymerization, Adv. Polym. Sci., 2006, 204, 1-154.

21 L. Friebe, O. Nuyken and W. Obrecht, A Comparison of Neodymium Versatate, Neodymium Neopentanolate and Neodymium Bis (2-ethylhexyl) phosphate in Ternary Ziegler Type Catalyst Systems With Regard to their Impact on the Polymerization of 1, 3-Butadiene, J. Macromol. Sci., Part A: Pure Appl. Chem., 2005, 42(7), 839-851.

22 A. Fischbach and R. Anwander, Rare-earth metals and aluminum getting close in Ziegler-type organometallics, Adv. Polym. Sci., 2006, 204, 155-281.
23 A. Fischbach, F. Perdih, P. Sirsch, W. Scherer and R. Anwander, Rare-earth Ziegler-Natta catalysts: carboxylatealkyl interchange, Organometallics, 2002, 21(22), 4569-4571.

24 A. Fischbach, E. Herdtweck, R. Anwander, G. Eickerling and W. Scherer, Reactivity of trimethylaluminum with lanthanide aryloxides: Adduct and tetramethylaluminate formation, Organometallics, 2003, 22(3), 499-509.

25 A. Fischbach, M. G. Klimpel, M. Widenmeyer, E. Herdtweck, W. Scherer and R. Anwander, Stereospecific polymerization of isoprene with molecular and MCM-48-Grafted Lanthanide(III) tetraalkylaluminates, Angew. Chem., Int. Ed., 2004, 43(17), 2234-2239.

26 A. Fischbach, F. Perdih, E. Herdtweck and R. Anwander, Structure-reactivity relationships in rare-earth metal carboxylate-based binary Ziegler-type catalysts, Organometallics, 2006, 25(7), 1626-1642.

27 Z. M. Sabirov, N. K. Minchenkova, V. N. Urazbaev and Y. B. Monakov, The mechanism of butadiene polymerization with the catalytic-system NdCl3.3TBP-(1C4H9)2AlH, J. Polym. Sci., Part A: Polym. Chem., 1993, 31(10), 2419-2421.

28 Z. M. Sabirov, Y. B. Monakov and G. A. Tolstikov, Kinetic Stereocontrol Of Polydiene Microstructures During Polymerization Of Nd-Al Bimetallic Systems, J. Mol. Catal., 1989, 56(1-3), 194-202.

29 H. Iovu, G. Hubca, E. Simionescu, E. Badea and J. S. Hurst, Butadiene polymerisation using binary neodymium-based catalyst systems. The effect of catalyst preparation, Eur. Polym. J., 1997, 33(6), 811-814.

$30 \mathrm{H}$. Iovu, G. Hubca, D. Racoti and J. S. Hurst, Modelling of the butadiene and isoprene polymerization processes with a binary neodymium-based catalyst, Eur. Polym. J., 1999, 35(2), 335-344.

31 G. Du, Y. Wei, L. Ai, Y. Chen, Q. Xu, X. Liu, S. Zhang, Z. Hou and X. Li, Living 3,4-Polymerization of Isoprene by Cationic Rare Earth Metal Alkyl Complexes Bearing Iminoamido Ligands, Organometallics, 2011, 30(1), 160-170.

32 J. Gromada, L. L. Pichon, A. Mortreux, F. Leising and J. Carpentier, Neodymium alk(aryl)oxides-dialkylmagnesium systems for butadiene polymerization and copolymerization with styrene and glycidyl methacrylate, J. Organomet. Chem., 2003, 683(1), 44-55.

33 U. Tracht and H. Kloppenburg, Modeling Nd-catalyzed butadiene rubber production, Macromol. Symp., 2007, 259, 76-84.

34 C. Ren, G. Li, W. Dong, L. Jiang, X. Zhang and F. Wang, Soluble neodymium chloride 2-ethylhexanol complex as a highly active catalyst for controlled isoprene polymerization, Polymer, 2007, 48(9), 2470-2474.

35 X. Jia, Y. Hu, Q. Dai, J. Bi, C. Bai and X. Zhang, Synthesis of syndiotactic cis-1, 4-polypentadiene by using ternary neodymium-based catalyst, Polymer, 2013, 54(12), 29732978.

36 R. Quirk, A. Kells, K. Yunlu and J.-P. Cuif, Butadiene polymerization using neodymium versatate-based catalysts: catalyst optimization and effects of water and excess versatic acid, Polymer, 2000, 41(15), 5903-5908. 
37 T. Yamamoto, T. Tanaka, T. Matsuyama, T. Funabiki and S. Yoshida, Alumina-supported rare-earth oxides characterized by acid-catalyzed reactions and spectroscopic methods, J. Phys. Chem. B, 2001, 105(9), 1908-1916.

38 M. P. Jensen and A. H. Bond, Comparison of covalency in the complexes of trivalent actinide and lanthanide cations, $J$. Am. Chem. Soc., 2002, 124(33), 9870-9877.

39 T. Yamamoto, T. Matsuyama, T. Tanaka, T. Funabiki and S. Yoshida, Silica-supported ytterbium oxide characterized by spectroscopic methods and acid-catalyzed reactions, $J$. Mol. Catal. A: Chem., 2000, 155(1), 43-58.

40 S.-W. Han, E. Stern, D. Haskel and A. Moodenbaugh, Local structure in the stripe phase of La 1.6-x Sr x Nd 0.4 CuO 4, Phys. Rev. B: Condens. Matter Mater. Phys., 2002, 66(9), 094101.

41 H. Guo, J. Bi, J. Wang, X. Zhang, S. Jiang and Z. Wu, Local structure analysis around $\mathrm{Nd}$ center in ternary catalyst comprising $\mathrm{Nd}($ vers $) 3, \mathrm{Al}(\mathrm{iBu}) 3$ and $\mathrm{Al}(\mathrm{iBu}) 2 \mathrm{Cl}$ by XAFS, Dalton Trans., 2015, 44(19), 9130-9139.

42 B. Ravel and M. Newville, ATHENA, ARTEMIS, HEPHAESTUS: data analysis for X-ray absorption spectroscopy using IFEFFIT, J. Synchrotron Radiat., 2005, 12(4), 537-541.

43 A. Ankudinov, B. Ravel, J. Rehr and S. Conradson, Real-space multiple-scattering calculation and interpretation of x-rayabsorption near-edge structure, Phys. Rev. B: Condens. Matter Mater. Phys., 1998, 58(12), 7565-7576.

44 A. D. Becke, Density-functional exchange-energy approximation with correct asymptotic behavior, Phys. Rev. A, 1988, 38(6), 3098-3100.

45 C. T. Lee, W. T. Yang and R. G. Parr, Development of the Colle-Salvetti correlation-energy formula into a functional of the electron density, Phys. Rev. B: Condens. Matter Mater. Phys., 1988, 37(2), 785-789.

46 M. J. Frisch, G. W. Trucks, H. B. Schlegel, G. E. Scuseria, M. A. Robb, J. R. Cheeseman, G. Scalmani, V. Barone, B. Mennucci, G. A. Petersson, H. Nakatsuji, M. Caricato, X. Li, H. P. Hratchian, A. F. Izmaylov, J. Bloino, G. Zheng, J. L. Sonnenberg, M. Hada, M. Ehara, K. Toyota,
R. Fukuda, J. Hasegawa, M. Ishida, T. Nakajima, Y. Honda, O. Kitao, H. Nakai, T. Vreven, J. A. Montgomery Jr, J. E. Peralta, F. Ogliaro, M. J. Bearpark, J. Heyd, E. N. Brothers, K. N. Kudin, V. N. Staroverov, R. Kobayashi, J. Normand, K. Raghavachari, A. P. Rendell, J. C. Burant, S. S. Iyengar, J. Tomasi, M. Cossi, N. Rega, N. J. Millam, M. Klene, J. E. Knox, J. B. Cross, V. Bakken, C. Adamo, J. Jaramillo, R. Gomperts, R. E. Stratmann, O. Yazyev, A. J. Austin, R. Cammi, C. Pomelli, J. W. Ochterski, R. L. Martin, K. Morokuma, V. G. Zakrzewski, G. A. Voth, P. Salvador, J. J. Dannenberg, S. Dapprich, A. D. Daniels, Ö. Farkas, J. B. Foresman, J. V. Ortiz, J. Cioslowski and D. J. Fox, Gaussian 09, Gaussian, Inc., Wallingford, CT, USA, 2009.

47 M. Hulsen, A. Weigand and M. Dolg, Quasirelativistic energy-consistent 4f-in-core pseudopotentials for tetravalent lanthanide elements, Theor. Chem. Acc., 2009, 122(1-2), 23-29.

48 A. V. Marenich, C. J. Cramer and D. G. Truhlar, Universal solvation model based on solute electron density and on a continuum model of the solvent defined by the bulk dielectric constant and atomic surface tensions, J. Phys. Chem. B, 2009, 113(18), 6378-6396.

49 Q.-Y. Wu, J.-H. Lan, C.-Z. Wang, C.-L. Xiao, Y.-L. Zhao, Y.-Z. Wei, Z.-F. Chai and W.-Q. Shi, Understanding the bonding nature of uranyl ion and functionalized graphene: a theoretical study, J. Phys. Chem. A, 2014, 118(11), 21492158.

50 Q.-Y. Wu, J.-H. Lan, C.-Z. Wang, Y.-L. Zhao, Z.-F. Chai and W.-Q. Shi, Understanding the interactions of neptunium and plutonium ions with graphene oxide: scalar-relativistic DFT investigations, J. Phys. Chem. A, 2014, 118(44), 1027310280.

51 Q.-Y. Wu, C.-Z. Wang, J.-H. Lan, Z.-F. Chai and W.-Q. Shi, Theoretical insight into the binding affinity enhancement of serine with the uranyl ion through phosphorylation, RSC Adv., 2016, 6(74), 69773-69781. 